\title{
Correlation between maternal and umbilical cord blood in pregnant women of Pokhara Valley: a cross sectional study
}

\author{
Sameer Timilsina ${ }^{1 *} \mathbb{D}$, Sirisa Karki ${ }^{2}$, Aajeevan Gautam³ ${ }^{3}$ Pujan Bhusal', Gita Paudel ${ }^{2}$ and Deepak Sharma ${ }^{1}$
}

\begin{abstract}
Background: Complete blood count is one of the routinely advised blood investigation during pregnancy. It is also utilized as a diagnostic tool for neonatal anemia, sepsis and determining hemostatic status of the newborn. The present study aims at estimating the complete blood count of maternal and umbilical cord blood at the time of delivery and to establish its correlation.

Method: This cross sectional study included 114 mothers and their healthy neonates born through normal vaginal delivery. Complete blood count of umbilical cord blood and maternal blood was estimated using automatic hematology analyzer.

Results: The mean maternal and neonatal hemoglobin concentration was $11.14 \pm 1.39 \mathrm{~g} / \mathrm{dL}$ and $16.34 \pm 2.01 \mathrm{~g} / \mathrm{dL}$ respectively. A significant positive correlation was found between maternal and fetal hemoglobin concentration ( $p<0.001$ and Pearson $R=0.496$ ). The correlation between maternal and fetal WBC, RBC and Platelet count was not statistically significant. A significant positive correlation was found between maternal and fetal MCV and MCH while PCV showed a non-significant positive correlation.

Conclusion: There was moderately positive correlation between maternal and fetal hemoglobin, MCV and MCH. The cord blood hemoglobin was lower in babies born to anemic mothers. The decrease in hemoglobin followed the severity of anemia, however, the correlation did not exist in anemic mothers. It suggested that fetal hematological parameters are not reflective of maternal hemogram.
\end{abstract}

Keywords: Hematology, Umbilical cord blood, Hemoglobin, Mother

\section{Background}

Maternal physiology endures several alterations in hematological parameters with an average rise of $40-50 \%$ in blood and plasma volume during pregnancy [1]. This hemodilution produces pronounced effect in hematocrit values. Complete blood count is the most commonly advised blood investigation. It is often the first step in evaluating hematologic function and diagnosis of related diseases [2]. During embryonic period, hematopoiesis occurs in different parts of the developing fetus. It starts initially in the embryonic yolk sack migrating to the fetal

\footnotetext{
*Correspondence: timilsina.sameer@cmc.edu.np; sawmer@gmail.com ${ }^{1}$ Department of Physiology, Chitwan Medical College, Tribhuwan University, Post Box No, Bharatpur-13, Chitwan 42, Nepal

Full list of author information is available at the end of the article
}

liver and preterm marrow. However, hematopoiesis is primarily restricted to the bone marrow in adults [3].

Anemia is a clinical condition in which the number of circulating red blood cells is insufficient to meet the body's physiologic demands. WHO classifies anemia [4] in pregnancy as non-anemic (>11 g/dL), mild anemia (10-10.9 g/dL), moderate anemia $(7-9.9 \mathrm{~g} / \mathrm{dL})$ and severe anemia $(<7 \mathrm{~g} / \mathrm{dL})$.

Umbilical cord blood hemoglobin is a dominant hematologic parameter of newborns at birth. Hemoglobin along with hematocrit values together have been customarily used in the diagnosis and follow-up of the neonatal anemia [5]. Besides this, other hematologic parameters like white blood cell count and platelet count are worthwhile in assessing neonatal sepsis and hemostatic status of infant [5]. Studies have shown some relationships between 
maternal and fetal hemogram but the extent of effect on maternal and neonatal health is still uncertain. This study was conducted to assess the effect of maternal hematologic profile during normal pregnancy on cord blood hematology.

In an attempt to achieving Millennium Development Goals (MDG) 4 and 5 Nepal has made noteworthy progress in the field of maternal, newborn and child health. Nepal Government has implemented certain health related policies like free ion supplementation and ANC visits even in the remote parts of the country. The policy also includes rewards for delivering babies in health care facilities. As a result, substantial improvement has been observed in maternal mortality rate plummeting from 450 in 2004 to 260 in 2014 [6]. As of yet, no studies have been conducted in Pokhara Valley of Nepal on maternal and neonatal hemogram. The present study aims at obtaining a complete picture of maternal and fetal hemogram thereby enabling to maintain referencing in the general population of this region. The anticipated advantage of this study was to determine the fetal outcomes beforehand and building up a strategy in order to prevent adverse outcomes.

\section{Methods}

This was a hospital based cross-sectional study conducted from April 2014 to March 2015 at Manipal Teaching Hospital, Pokhara (827 m above sea level), Nepal. A total of 114 normal singleton pregnant mothers and their healthy newborn babies were included in the study. All pregnant women were residents of Pokhara Valley. They all have had 4 routine antenatal checkups during the course of pregnancy and all of them were supplemented with iron and folic acid. A written consent was obtained from the mother for participation in the study for both the mother and their newborn child. A brief history of the mother was taken during presentation for delivery. $3 \mathrm{ml}$ of blood was collected in a sterile syringe from ante cubital vein and stored in an EDTA containing vial. After $2 \mathrm{~min}$ of delivery of the baby, $3 \mathrm{ml}$ of umbilical cord blood was collected and was stored in an EDTA containing vial. Upon collection of the sample, it was analyzed within 3-6 h using an automatic hematology analyzer (Diagnova RFCL lablife h3d premier). Appropriate internal quality controls were run before assay of samples. Statistical analysis was performed by using the program Statistical Packages of Social Sciences (SPSS) version 20.0. The results were evaluated by using Pearson correlation test and Independent sample ' $t$ ' test. Shapiro Wilk test was done to check the normality of distribution of different variables. Multiple regression analysis was performed for multivariate analysis. Statistical significance was considered at $p<0.05$.

\section{Results}

The study included a total of 114 pregnant women and their newborns ( 86 males and 28 females). Of the total participants, $68(59.64 \%)$ were multi gravida and $46(40.36 \%)$ were primigravida. The mean age of pregnancy was $26.04 \pm 3.47$ years with $86 \%(98 / 114)$ between the age of 21-30 years. The result presented here affirms the existence of variations in red cell indices of umbilical cord blood reported for Pokhara

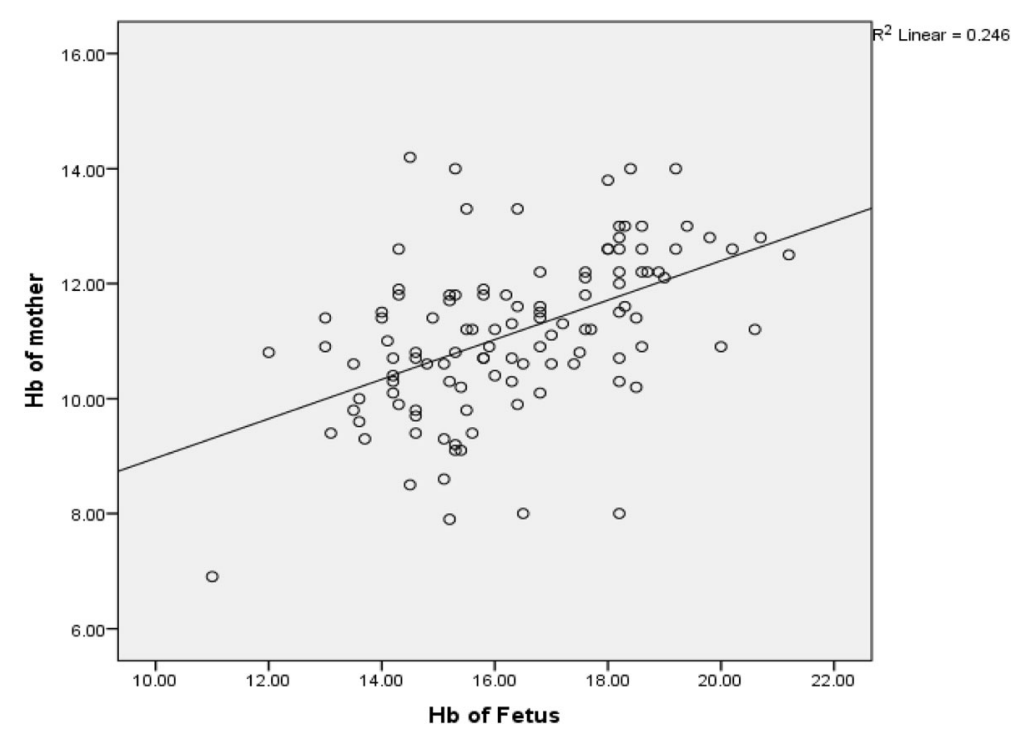

Fig. 1 Scatter plot showing mean hemoglobin concentration of maternal and umbilical cord blood 


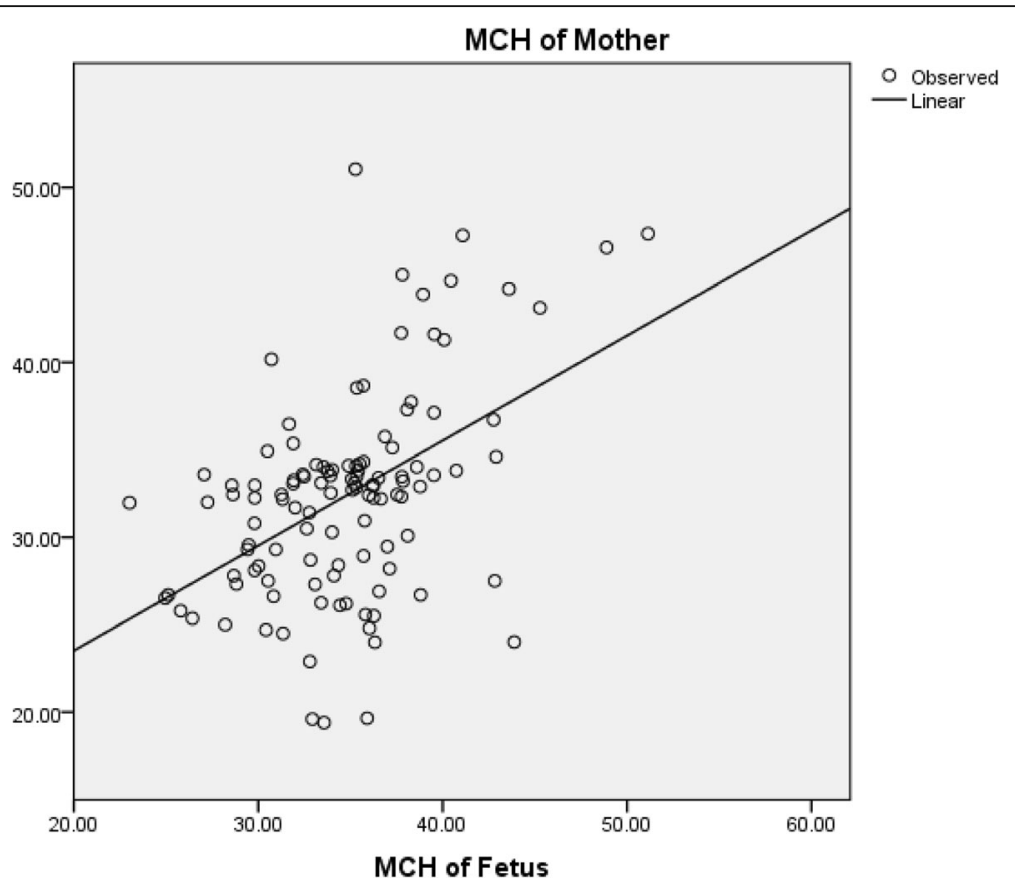

Fig. 2 Scatter plot showing mean MCH concentration of maternal blood and umbilical cord blood

valley of Nepal. These results could be helpful in providing a baseline data for further studies as to establish a reference value for maternal and umbilical cord hemogram in the locality.

The result showed no significant correlation between total white blood cell count of mother with that of the fetus $(p>0.01)$. The normally distributed variables were hemoglobin, RBC count, hematocrit, MCV and platelets while the remaining variables were non-normally distributed.

The mean maternal hemoglobin concentration was $11.14 \pm 1.39 \mathrm{~g} / \mathrm{dL}$. According to the WHO classification of anemia in pregnant women, $46.49 \%$ of the participants were found to be anemic. The mean hemoglobin concentration of umbilical cord blood was found to be $16.34 \pm 2.01 \mathrm{~g} / \mathrm{dL}$. The mean cord blood hemoglobin concentration in anemic and nonanemic mothers was $15.38 \pm 1.7 \mathrm{~g} / \mathrm{dL}$ and $17.21 \pm$ $1.87 \mathrm{~g} / \mathrm{dL}$ respectively. Figure 1 represents the scatter plot of mean hemoglobin of mother with that of the umbilical cord blood showing a linear correlation which was found to be statistically significant $(p<$ 0.05). Likewise, Fig. 2 shows the scatter plot of mean $\mathrm{MCH}$ of mother with that of the umbilical cord blood indicating a linear correlation and was also found to be statistically significant (Tables 1 and 2).

Multivariate analysis showed maternal factors like age, gravida and smoking history did not influence the hematological parameters of the fetus. As all pregnant mothers were supplemented with iron and folic acid, ion supplementation was not considered as a confounding factor to umbilical cord hemogram.

Table 1 Mean Hemoglobin concentration of mothers in reference to classification of anemia by WHO.

\begin{tabular}{|c|c|c|c|c|}
\hline $\begin{array}{l}\text { Maternal Hemoglobin g/dL } \\
\text { (WHO Classification) }\end{array}$ & $\begin{array}{l}\text { Mean maternal Hemoglobin } \\
\mathrm{g} / \mathrm{dL}\end{array}$ & No of patients & $\begin{array}{l}\text { Pearson's correlation } \\
\text { coefficient R }\end{array}$ & $p$ value \\
\hline $\begin{array}{l}\text { Non anemic } \\
\mathrm{Hb}>11 \mathrm{~g} / \mathrm{dL}\end{array}$ & $12.17 \pm 0.81$ & 60 & 0.460 & $p<0.05$ \\
\hline $\begin{array}{l}\text { Mild anemia } \\
\mathrm{Hb}=10-10.9 \mathrm{~g} / \mathrm{dL}\end{array}$ & $10.57 \pm 0.27$ & 33 & 0.456 & $p<0.05$ \\
\hline $\begin{array}{l}\text { Moderate Anemia } \\
\mathrm{Hb}=7-9.9 \mathrm{~g} / \mathrm{dL}\end{array}$ & $9.18 \pm 0.65$ & 20 & 0.499 & $p<0.05$ \\
\hline $\begin{array}{l}\text { Severe anemia } \\
\mathrm{Hb}<7 \mathrm{~g} / \mathrm{dL}\end{array}$ & .......... & 1 & $\ldots \ldots$ & ......... \\
\hline
\end{tabular}


Table 2 Correlation between maternal and fetal hemogram

\begin{tabular}{|c|c|c|c|c|}
\hline Parameters & Mother & Fetal & Pearson's correlation coefficient R & $p$-value \\
\hline 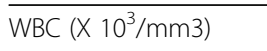 & $10.20 \pm 3.36$ & $15.52 \pm 5.60$ & -0.040 & NS \\
\hline $\mathrm{Hb}(\mathrm{g} / \mathrm{dL})$ & $11.14 \pm 1.39$ & $16.34 \pm 2.01$ & 0.496 & $p<0.001$ \\
\hline $\left.\mathrm{RBC} \times 10^{6} / \mathrm{mm}^{3}\right)$ & $4.04 \pm 0.46$ & $4.72 \pm 0.59$ & 0.083 & NS \\
\hline Hematocrit (\%) & $33.29 \pm 4.02$ & $48.79 \pm 6.88$ & 0.109 & NS \\
\hline MCV (fL) & $82.33 \pm 6.46$ & $102.85 \pm 8.58$ & 0.058 & NS \\
\hline $\mathrm{MCH}(\mathrm{pg})$ & $33.34 \pm 5.94$ & $34.70 \pm 4.73$ & 0.478 & $p<0.001$ \\
\hline $\mathrm{MCHC}(\mathrm{g} / \mathrm{dL})$ & $33.40 \pm 1.25$ & $33.26 \pm 1.09$ & -0.069 & NS \\
\hline Platelets (X 104/mm3) & $22.29 \pm 6.61$ & $229.20 \pm 73.39$ & 0.005 & NS \\
\hline
\end{tabular}

\section{Discussion}

The mean age of pregnancy was found to be $26.04 \pm$ 3.47 years and the median age was 26 years which was slightly above the national data of census of Nepal 2011. WHO's [4] report of 44\% prevalence of anemia in Nepal was consistent with the present study. The result of the present study was homogenous to WHO survey for mean hemoglobin concentration of average Nepali pregnant women estimated at $11.1 \mathrm{~g} / \mathrm{dL}(10.8-11.5 \mathrm{~g} / \mathrm{dL}$ with $95 \%$ credibility interval) [4]. Similar to studies in other parts of the country, [7-10] $45.61 \%$ of pregnant women were found to have hemoglobin concentrations less than $10 \mathrm{~g} / \mathrm{dL}$ and $0.8 \%$ with hemoglobin concentration less than $7 \mathrm{~g} / \mathrm{dL}$. This finding was far from similar to the 2016 Nepal DHS Key indicators [11] which reported anemia in this part of Nepal to be around $28 \%$. The prevalence of anemia throughout the country is however similar to the present study (46\%). [10].

The present study showed significant positive correlation between maternal and fetal hemoglobin concentrations like Dapper DV et al. [12] in Nigeria, McElroy PD et al. [13] in Kenya, and Alizadeh L et al. [14] in Iran. No significant correlation was observed between maternal and fetal white cell count and MCHC [12-14]. A positive linear Pearson correlation was observed between mean hemoglobin and PCV of cord blood and maternal blood. All these results were similar to the ones observed by Nneli $R$ et al. [15] Singla PN et al. [16] and Al-hilli NM et al. [17]. In contrast to the present study, some previous investigators including Qaiser DH et al., [18] Kilbride J et al., [19] and Mamoury GH et al. [20] have failed to find a relationship between the maternal and cord blood hemoglobin.

The present study showed $5.7 \%$ of the fetuses had low hemoglobin concentration, 23.94\% had low MCV, $18.24 \%$ had low $\mathrm{MCH}$ and none of the fetuses had low $\mathrm{MCHC}$ which was a constant finding with Abdelgader
EA et al. [21] and Steer PJ [22]. The cord blood hemoglobin $(16.8 \mathrm{~g} / \mathrm{dL})$ of healthy term neonates in this study was uniform with those reported from studies in the west [23, 24].

Qaiser DH et al. [25] measured the mean of all CBC parameters aiming to maintain refrencing, and found the mean hemoglobin $=14.99 \pm 1.47 \mathrm{~g} / \mathrm{dL}, \mathrm{RBC}=4.29 \pm 0.44$, $\mathrm{PCV}=45.65 \pm 4.83, \mathrm{MCV}=105.81 \pm 6.24, \mathrm{MCH}=34.96$ $\pm 2.11, \quad \mathrm{MCHC}=32.47 \pm 2.12, \quad \mathrm{TC}=13.61 \pm 4.23 \quad$ and platelet count $=256.25 \pm 76.54$ in the umbilical cord blood. The result showed similar findings with the present study but with a slightly higher total WBC count.

As the study was conducted in only one tertiary care center and that too with a limited number of patients, the result does not represent the pregnant women in Western Development Region of Nepal. Also, the study only included the patients attending hospital for delivery so the results cannot be generalized as it may not be a true reflection of the general population. However researchers have found the increasing trend of hospital based deliveries in urban population and Pokhara being an urban city, the data and results presented could actually represent the urban population of Pokhara valley. Socioeconomic status of the pregnant women was also not considered in the study. Moreover, further studies are to be conducted in the field to achieve complete results.

\section{Conclusions}

There was moderately positive correlation between maternal and fetal hemoglobin, $\mathrm{MCV}$ and $\mathrm{MCH}$. There was a decrease in the cord blood hemoglobin in different severities of anemia, however, the correlation between maternal and fetal hemoglobin did not exist. It suggested that the fetal hematological parameters are not reflective of maternal hemogram.

Anemia in pregnancy should be properly evaluated and treated accordingly in order to avoid unwanted fetal and maternal outcomes. 


\section{Abbreviations}

ANC: Ante-natal Checkup; CBC: Complete Blood Count; EDTA: Ethylene Diamine Tetra Acetic acid; Hb: Hemoglobin; MCH: Mean Corpuscular Hemoglobin; MCHC: Mean Corpuscular Hemoglobin Concentration; MCV: Mean Corpuscular Volume; MDG: Millennium Development Goals; PCV: Packed Cell Volume; RBC: Red Blood Cells; SPSS: Statistical Package for Social Sciences; TC: Total Count; WBC: White Blood Cells; WHO: World Health Organization

\section{Acknowledgements}

We would like to thank the ethical committee of Manipal College of Medical Sciences for providing us the consent to conduct this study at this esteemed institute. We would also like to whole heartedly thank the participants of the study without whom the study would not have been possible. We are highly indebted to Prof Dr. C G Saha, HOD and all faculties of Department of Physiology, Manipal College of Medical Sciences for their continuous encouragement and support in the field of research. We would also like to thank Dr. Indu Tiwari, Mr. Bhuwan Baskota and Mr. Madhav Poudel for their help and support. Our sincere gratitude to Dr. Santosh Timalsina for his untiring and ever encouraging words during data analysis. Also, we would like to thank Dr. Nikki Shrestha for her English language assistance.

\section{Funding}

No funding of any sort was received for the study.

\section{Availability of data and materials}

The datasets obtained and/or analyzed during the current study are not publicly available due to confidentiality consent of the study but can be obtained from the corresponding author on reasonable request.

\section{Authors' contributions}

ST wrote the proposal, participated in data collection, analyzed the data and drafted the paper. SK assisted in data collection, laboratory procedures and helped in revising the draft. AG and PB helped in the analysis of the data and writing manuscript. GP and DS participated in manuscript editing and final writing. All authors read and approved the final manuscript.

\section{Ethics approval and consent to participate}

Ethical approval was obtained from the Ethics and Research Committee, Manipal College of Medical Sciences, Pokhara, Nepal. A written consent was obtained from the mother for participation in the study of both the mother and their newborn child. It was clearly informed verbally and in written that there would be no potential harm to the mother or the newborn baby while performing the blood tests. The consent also informed the participants that the data obtained could be used and made public under anonymity. All procedures were in accordance with the Helsinki declaration and its later amendments.

\section{Consent for publication}

Not Applicable

\section{Competing interests}

The authors declare that they have no competing interests.

\section{Publisher's Note}

Springer Nature remains neutral with regard to jurisdictional claims in published maps and institutional affiliations.

\section{Author details}

'Department of Physiology, Chitwan Medical College, Tribhuwan University, Post Box No, Bharatpur-13, Chitwan 42, Nepal. ${ }^{2}$ Department of Pharmacology, Chitwan Medical College, Tribhuwan University, Bharatpur-13, Chitwan, Nepal. ${ }^{3}$ Department of Anatomy, Chitwan Medical College, Tribhuwan University, Bharatpur-13, Chitwan, Nepal.

Received: 1 March 2017 Accepted: 2 March 2018 Published online: 21 March 2018

\section{References}

1. Pritchard JA. Changes in blood volume during pregnancy and delivery. Anesthesiology. 1965;26:393.
2. eMedicine Health [Internet]. Nabili SM.: @2015 Web MD. Complete blood count (online). 2017 Feb 21 Available from URL: http://www. emedicinehealth.com/complete_blood_count_cbc/article_em.htm

3. Fristma GA, Keohane E. Hematology: Clinical principles and applications. 4th ed. New York: Elsevier Health Sciences; 2012.

4. WHO. The global prevalence of anaemia in, vol. 2011. Geneva: World Health Organization; 2015.

5. Paiva AD, Rondo PH, Pagliuisi RA, Latorre MR, Cardoso MA, Gondium SS. Relationship between the iron status of pregnant women and their newborns. Rev Saude Publica. 2007;41:321-7.

6. Ministry of Health and Population Nepal. Partnership for Maternal, Newborn \& Child Health, WHO, World Bank and Alliance for Health Policy and Systems Research. Success factors for women's and children's health: Nepal. Geneva: World Health Organisation; 2014.

7. Bhandary S, Shrestha A. Prevalence of anemia among non-pregnant and pregnant women of reproductive age in Nepal. JGPEMN. 2011 Jan-June;2: 21-6.

8. Rana SS, Sharma S, Chand A, Malla R. Relationship between maternal Haemoglobin and fetal weight. NJOG. 2013 Jan-Jun;8(1):37-40.

9. Raut BK, Jha MK, Shrestha A, Sah A, Sapkota A, Byanju S, et al. Prevalence of iron deficiency anemia among pregnant women before iron supplementation in Kathmandu University/ Dhulikhel hospital. Journal of Gynecology and obstetrics. 2014;2(4):54-8

10. Tuladhar $\mathrm{H}$. Anaemia in adolescent pregnancy. JNMC. 2000 Jan;2(1):19-21.

11. Ministry of Health, Nepal; New ERA; and ICF. Nepal demographic and health survey 2016: key indicators. Kathmandu, Nepal: Ministry of Health, Nepal; 2017

12. Dapper DV, Didia BC. Haemorheological parameters of umbilical cord blood of Nigerian newborns: correlations with maternal parameters. WAJM JanMar. 2006;25(1):226-30.

13. McElroy PD, Lal AA, Hawley WA, Bloland PB, Kuile OAJ, et al. Analysis of repeated hemoglobin measures in full-term, normal birth weight Kenyan children between birth and four years of age. The ASEMBO Bay cohort project. Am J Trop Med Hyg. 1999;61(6):932-40.

14. Alizadeh L, Raoofi A, Salehi L, Ramzi M. Impact of maternal hemoglobin concentration on fetal outcomes in adolescent pregnant women. Iran Red Crescent Med J. 2014 Aug 1:16(8):e19670.

15. Nneli R, Amadi S, Nwafia W. Certain red blood cell indices of maternal and umbilical cord blood in Owerri, Nigeria: a preliminary report. Ann Med Health Sci Res 2011 Jan;1(1):1-8.

16. Singla PN, Chand S. Effect of maternal anaemia on the placenta and the newborn infant. Acta Paediatr. 2008 June:67(5):645-8.

17. Al-hilli NM. The Effect of Maternal Anaemia on Cord Blood Haemoglobin \& Newborn Birth Weigh Karbala. J Med. 2010;2:8-9.

18. Qaiser DH, Sandhila MP, Omair A, Ghori GM. Correlation of routine Haematological parameters between normal maternal blood and the cord blood of healthy newborns in selected hospitals of Karachi. J Coll Physicians Surg Pak. 2013 Feb:23(2):128-31.

19. Kilbride J, Baker TG, Parapia LA, Khoury SA, Shuqaidefd SW, Jerwoode D. Anaemia during pregnancy as a risk factor for iron-deficiency anaemia in infancy: a case-control study in Jordan. Int J Epidemiol. 1999 June;28:461-8.

20. Mamoury GH, Hamedy AB, Alkhlaghi F. Cord haemoglobin in newborn in correlation with maternal haemoglobin in northeastern Iran. Iran J Med Sci. 2003:28:166-8

21. Abdelgader EA, Sana E, Abdalla SE, Kordofani AA, Omer IM. Haematological pictures in full term new born children in Sudan. Basic research journal of medicine and clinical. Sciences. 2013 Oct;2(9):88-93.

22. Steer PJ. Maternal hemoglobin concentration and birth weight. Am J Clin Nutr 2000 May;71(5 Suppl):1285S-1287S.

23. Doyle JJ, Schmitdt B, Avery GB, Fletcher MA, Macdonald MG. Neonatology, pathophysiology management of the newborns. 5th ed. Philadelphia: Lippincott; 1999.

24. Chirstenson RD. Expected hematologic values for term and preterm neonates. In: Cristensen P, editor. Hematologic problems of the neonatel. 11 th ed. Philadelphia: Saunders; 2005. p. 118-22.

25. Qaiser DH, Ahmed ST, Sandila MP, Kazmi T. Hematological reference values for full term, healthy, newborns of Karachi. Pakistan JPMA. 2009;59:618. 